\title{
Coronavirus Disease 2019 (COVID-19) as a Multi-Systemic Disease and its Impact in Low- and Middle-Income Countries (LMICs)
}

\author{
Mazou Ngou Temgoua ${ }^{1}$ • Francky Teddy Endomba ${ }^{2}$ • Jan René Nkeck ${ }^{1} \cdot$ Gabin Ulrich Kenfack ${ }^{1}$. \\ Joel Noutakdie Tochie ${ }^{3} \cdot$ Mickael Essouma $^{1}$
}

Accepted: 13 July 2020 / Published online: 20 July 2020

(C) Springer Nature Switzerland AG 2020

\begin{abstract}
Currently, the coronavirus disease 2019 (COVID-19) is the priority of the global health agenda. Since the first case was reported in Wuhan, China, this infection has continued to spread and has been considered as a pandemic by the World Health Organization (WHO) within 3 months of its outbreak. Several studies have been done to better understand the pathogenesis and clinical aspects of the disease. It appears that COVID-19 affects almost all body organs due to the direct effect of the virus and its induced widespread inflammatory response. This multi-systemic aspect of the disease has to be inculcated in COVID-19 management by health providers to improve patient outcomes. This strategy could help curb the burden of the disease especially in low- and middle-income countries (LMICs) like most African countries where the pandemic is at an "embryonic" stage.
\end{abstract}

Keywords Coronavirus disease 2019 • Multi-systemic disease · Therapeutical implication · Low- and middle-income countries

\section{Introduction}

The coronavirus disease 2019 (COVID-19) is a global emergency due to a beta coronavirus called severe acute respiratory syndrome-coronavirus 2 (SARS-CoV-2) [1]. COVID-19 first emerged in China in December 2019 as a respiratoryinfectious epidemic. Strikingly, within 3 months of its outbreak, COVID-19 had rapidly spread worldwide like no unprecedented infection, infecting 1.2 million persons and claiming 70,000 deaths. Consequently, WHO declared this highly contagious and potentially fatal communicable disease a pandemic on March 3, 2020 [2]. This pathology is mainly

This article is part of the Topical Collection on Covid-19

Mazou Ngou Temgoua

neurotemgoua@yahoo.fr

1 Department of Internal Medicine and Specialities, Faculty of Medicine and Biomedical Sciences, University of Yaounde, Yaoundé, Cameroon

2 Psychiatry Internship Program, University of Bourgogne, 21000 Dijon, France

3 Department of Anesthesiology and Critical Care Medicine, Faculty of Medicine and Biomedical Sciences, University of Yaounde, Yaoundé, Cameroon transmitted through droplets into the air from infected patients (during coughing, sneezing, and speaking) or contact with contaminated surfaces. Aerosol transmission is also possible in case of protracted exposure to elevated aerosol concentrations in closed spaces [3]. Once the pathogen (SARS-CoV-2) enters the human body, it invades the alveoli and links to the angiotensin-converting enzyme 2 (ACE2) receptor of type 2 pneumocytes through their spike protein [4]. Diverse manifestations of the disease are due to the direct effects of the virus or inflammatory mediators especially IL1, IL6, and TNF-alpha. SARS-CoV-2 induces an alveolar-interstitial inflammation with a high risk of acute pulmonary edema or acute respiratory distress syndrome. It is worth to mention that the pathogenesis of COVID-19 also entails a systemic inflammation with several consequences detailed in Table 1 . The incubation period of the virus varies from 2 to 14 days [5], and the major symptoms of the disease include fever $(88.7 \%)$, cough $(67.8 \%)$, fatigue $(38.1 \%)$, sputum production $(33.4 \%)$, shortness of breath $(18.6 \%)$, sore throat $(13.9 \%)$, and headache (13.6\%). Asymptomatic and mild cases represent $81 \%$ of cases of COVID-19, and severe cases account for $14 \%$ and critical cases $5 \%$ of all infected patients [4]. Vulnerable groups include patients with advanced age, hypertension, diabetes, obesity, cancer, pregnancy, and chronic kidney disease [1, 4]. Severe complications of the disease are due to multiple systemic involvements [6]. 


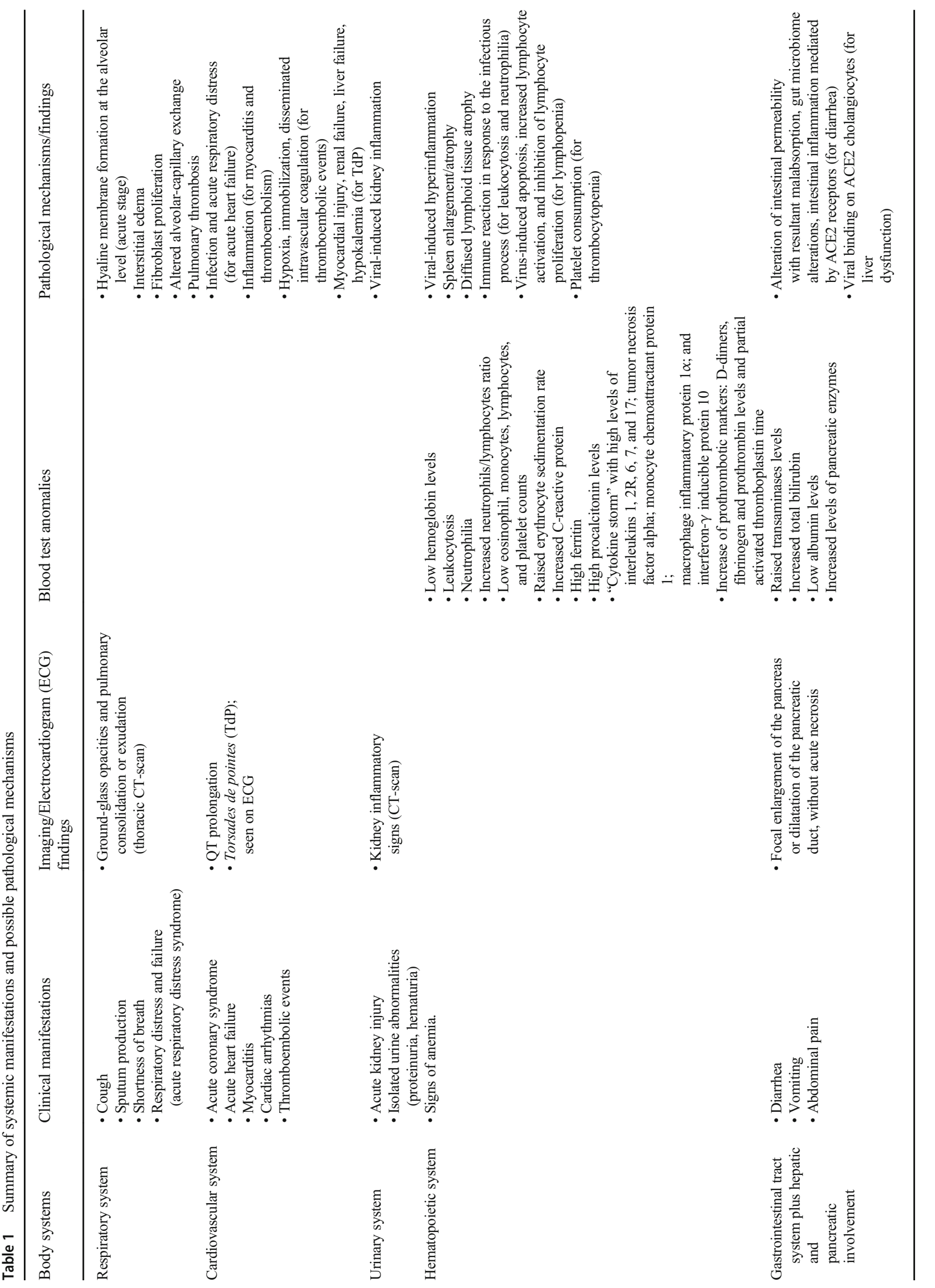




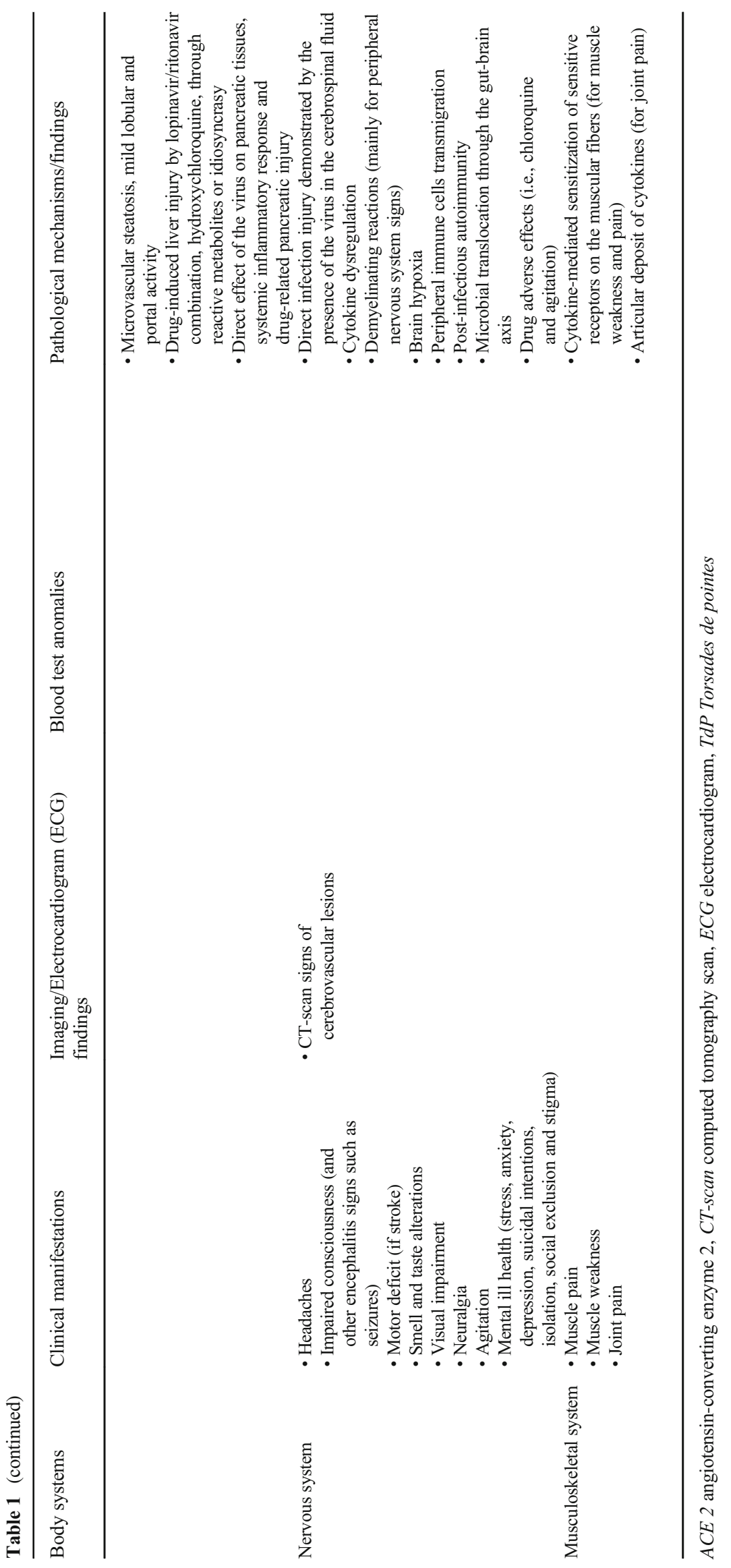


At this writing, no curative treatment or vaccine has been found for COVID-19 despite several research works done on this pathology. Researchers have also sought to better understand the interactions of COVID-19 with all the various cells and organs of the body. However, with an extensive literature search, to the best of our knowledge, there is no summarized literature of diverse aspects of the disease and therapeutic implications in LMICs. We propose this review to illustrate the various interactions of COVID-19 as a systemic disease whose implications need to be considered in the management of infected critically ill patients in challenged-resource settings.

\section{Methods}

This review is a summarized literature on diverse clinical aspects and therapeutic implications of COVID-19 in LMICs. The authors who are specialists in internal medicine, cardiology, rheumatology, psychiatry, and hepato-gastroenterology have proceeded by independent critical analysis of existing literature on PubMed, Google Scholar, Embase, and Cochrane Library.

\section{State of Knowledge}

\section{The Respiratory Pattern of COVID-19}

As an airborne disease, COVID-19 expresses itself mainly by respiratory symptoms. Guan et al. found in a large cohort of 7736 patients with COVID-19 observed that the second most common symptom after fever was cough (67.8\%), sputum production (33.4\%), and shortness of breath (18.6\%) [4]. A systematic review of the clinical aspect of COVID-19 done by Mao et al. reported the same data with an analysis of 34 published articles. The respective prevalence of respiratory signs was cough $(63.9 \%)$, sputum production $(28.9 \%)$, and shortness of breath (19.7\%). The most severe clinical presentation was respiratory distress in $14 \%$ and 5\% for respiratory failure [7]. The patterns on chest imaging findings were ground-glass opacity $(60.9 \%)$ and pulmonary consolidation or exudation (37\%), unilateral pneumonia (19.5\%), and bilateral pneumonia in $68.8 \%$ [8]. Patients suffering from chronic respiratory diseases (COPDs), especially asthma, have been reported to have more adverse outcomes compared to COVID-19 patients without COPD [9]. But allergic diseases in general seem to convey protection for severe COVID-19 disease probably because of reduced ACE2 gene expression in the alveoli [10]. The severity of the disease is related to massive alveolar damage that results to acute respiratory distress syndrome (ARDS) defined as a hypoxemic respiratory difficulty refractory to treatment, usually of gradual onset over 1 week, and associated with $\mathrm{PaO}_{2} / \mathrm{FiO}_{2} \leq 300 \mathrm{mmHg}$ and noncardiogenic pulmonary edema $[1,4,11]$. Post-mortem histopathological pulmonary examinations of COVID-19 patients who died of ARDS have shown hyaline membrane formation in the alveoli in the acute stage, and this was followed by interstitial widening, edema, and then fibroblast proliferation in the organizing stage of the disease [12]. These structural modifications are probably the main cause of the alteration in the alveolar-capillary exchange leading to severe respiratory distress (1). Pulmonary thrombosis is also common in sepsisinduced ARDS and contributes to aggravating the on-going respiratory failure [13]. These findings illustrate the interaction between the cardiovascular and respiratory systems.

\section{The Cardiovascular Aspect of COVID-19}

After the respiratory system, the second most affected body system known by COVID-19 is the cardiovascular system [14]. It has been reported that patients who have cardiovascular risk factors are at increased risk to develop severe complications, and many patients have died of cardiovascular events. Several studies have shown that patients who are at an increased risk of death are those with cardiovascular risk factors like: age $>60$ years, obesity, hypertension, and diabetes mellitus [4, 14]. Apart from predisposition to atherosclerosis and related risk of ischemic heart disease, specific mechanisms have been investigated. SARS-CoV-2 bind to their target cells through ACE 2, which are expressed by epithelial cells of the lungs, intestines, kidneys, and blood vessels [15]. The expression of ACE 2 may be substantially increased in patients with type 1 or type 2 diabetes and hypertension [16]. Obesity plays an important role in the pathogenesis and severity of COVID-19 infection. Hyperexpression of ACE 2 has been found in this population leading to increased vulnerability to the infection. Also, obese patients have a higher risk of respiratory distress and major risk of systemic inflammation [17]. Another important concern is the association of COVID19 with thromboembolism events, a major contributor to the death toll of COVID-19 [18]. Some cardiovascular diseases associated with COVID-19 include myocarditis, heart failure, cardiac arrhythmias, and acute coronary syndrome as direct consequences of systemic inflammation. On the other hand, heart failure is generally secondary to infection and acute respiratory distress [19]. Cardiac arrhythmia, one expression of cardiac involvement, is highly prevalent in COVID-19 patients. In a study done by Wang et al., $44.4 \%$ of patients admitted in the intensive care unit (ICU) had cardiac arrhythmia [11]. The main type of arrhythmia which led to the death of patients was torsade de pointes (TdP), secondary to QT prolongation. Some iatrogenic and comorbidities that increase the risk of QT prolongation in COVID-19 patients are drugs (like hydroxychloroquine), myocardial injury, renal failure, hepatic failure, and electrolytic imbalance such as 
hypokalemia [20]. COVID-19 is also associated with venous thromboembolism; Klok et al. found in a total of 184 patients admitted in ICU in Holland and 27\% developed thromboembolic complications [13]. The potential mechanisms associated with thromboembolism in COVID-19 could be excessive inflammation, hypoxia, immobilization, and diffused intravascular coagulation. The risk may be enhanced in patients with known thromboembolic risk factors like old age, obesity, malignancy, and pregnancy, and this probably explains the risk of death in this population [13].

\section{Renal Manifestations with COVID-19 Disease}

Reports from several Chinese studies have shown SARSCoV-2 replication in kidneys in almost $30 \%$ of patients with COVID-19, indicating a high tropism for the kidneys. Indeed, ACE 2 receptors which facilitate viral entry are highly expressed in the brush border of proximal tubular cells and to a less extent in podocytes [21-24]. Resultantly, both subjects with and without pre-existing kidney disease may present with renal manifestations in the setting of COVID-19. However, chronic kidney disease (CKD) and kidney transplantation may increase the risk for COVID-19, even though CKD patients might overall experience a mild disease as a result of immunosuppression [23, 25]. This does not seem to be the case with kidney-transplant recipients since recent evidence from a study conducted at the Montfire Medical Center in USA affirms a severe disease course in this specific group [25]. They reported severe disease in 28 of 36 kidneytransplant recipients seen with COVID-19 in their center between March 16 and April 1, 2020. Of the 36 kidneytransplant recipients, 10 had a fatal postoperative outcome after a median follow-up of 21 days (range, 14 to 28 days): Seven out of the 10 deceased patients were on mechanical ventilation before their death, indicating the degree of their critical illness. The spectrum of renal manifestations in COVID-19 varies, including acute kidney injury (global incidence, $11 \%$ ), proteinuria ( 7 up to $63 \%$ of cases) hematuria, increased kaliuresis, and the presence of SARS-CoV-2 in the urine. Specific SARS-CoV-2-mediated histological lesions of kidneys include markers of direct parenchymal infection (e.g., virus particles), isolated erythrocyte aggregation/obstruction in the lumen of glomerular and peritubular capillaries, glomerular and endothelial cell injury, myoglobin/cellular debris casts, and rhabdomyolysis. All these manifestations may be underpinned by specific and non-specific mechanisms. Specific mechanisms include direct viral entry, imbalanced renin-angiotensin system, and pro-inflammatory cytokines elicited by the viral infection and thrombotic events. Nonspecific mechanisms include hemodynamic alterations, right heart failure, high levels of PEEP in patients requiring mechanical ventilation, hypovolemia, administration of nephrotoxic drugs, and nosocomial sepsis [24].
Immunohematological Manifestations with COVID-19 Disease

Currently, there is scant evidence on COVID-19 in subjects with hematological and generalized immunosuppression/ autoimmune diseases. However, all immunohematological manifestations of COVID-19 occur in the general population [26-33]. Whilst clinical abnormalities resulting from virally induced hyperinflammation include spleen enlargement/ atrophy and diffuse lymphoid organ atrophy, biological abnormalities involve both blood/immune cells and soluble plasma molecules [26-33].

Abnormalities of blood/immune cells are mostly quantitative and include anemia, leukocytosis, neutrophilia, increase in neutrophils/lymphocytes ratio, and low eosinophil, monocytes, lymphocytes (T CD4/CD8), and platelet counts [26, 29]. Anemia is likely due to hyperinflammation [26]. Leukocytosis and neutrophil elevation secondary to bacterial infections were found in $11.4 \%$ of patients with severe disease versus $4.8 \%$ in those with mild to moderate disease in a review by Lippi et al. [29]. Lymphopenia may result from three mechanisms: virus-induced apoptosis, increased lymphocyte activation, and inhibition of lymphocyte proliferation [26, 29, 33]. Thrombocytopenia can be found in up to $57.7 \%$ of patients with severe disease versus $31.6 \%$ of those with mild diseases and is likely due to excess platelet consumption in peripheral sites of microthrombosis [29].

Abnormalities of soluble molecules can be grouped in two main syndromes: inflammatory syndrome and prothrombotic state [27-29, 33]. The inflammatory syndrome resembles that seen in classic hyper ferritinemic syndromes, i.e., macrophage activation syndrome, catastrophic antiphospholipid syndrome, septic shock, and adverse reaction to the biological compound anti-CD-28 [27, 32]. This inflammatory syndrome comprises of raised erythrocyte sedimentation rate, increased C-reactive protein, high ferritin and procalcitonin levels, and the "cytokine storm" [26, 27, 33]. The cytokine storm, which is characterized by increased serum levels of proinflammatory cytokines (interleukins 1, 2R, 6, 7 and 17; tumor necrosis factor alpha, monocyte chemoattractant protein 1 , macrophage inflammatory protein $1 \alpha$, interferon- $\gamma$ inducible protein 10 ), is associated with high mortality likely due to acute lung injury and multiple organ dysfunction [26, 32, 33]. Noteworthy, it has been postulated that the mortality is directly linked to SARS-CoV-2-driven hyper inflammation [32]. However, a compensatory anti-inflammatory response is also seen in patients with severe COVID-19 as evidenced by increased serum IL-10 signature, thus leading to high rates of secondary bacterial infections in those patients [26]. Prothrombotic markers in COVID-19 patients include increased D-dimers, fibrinogen, and prothrombin levels, as well as partial activated thromboplastin time [26, 33]. Recently, antiphospholipid antibodies namely IgA anticardiolipin and 
type 1 anti- $\beta 2$ glycoprotein ( $\operatorname{IgA}$ and $\operatorname{IgG}$ ) have been found in sera of older male Chinese patients. The brain imaging of all these patients who also had cardiovascular comorbidities (hypertension in all and diabetes mellitus in two) showed cerebral infarcts [30].

\section{COVID-19 and the Gastrointestinal Tract, Liver, and Pancreas}

COVID-19 can present with only gastrointestinal symptoms [34]. Approximately $20 \%$ of COVID- 19 patients present specific gastrointestinal symptoms in the following order of decreasing frequency: diarrhea, vomiting, and abdominal pain [34]. Diarrhea usually lasts from 1 to 14 days with a frequency of about 5 bowel movements per day [35]. The specific mechanism involved in diarrhea pathogenesis is not entirely known [36]. Viral entry into the enterocyte epithelial cell is done by an interaction between envelope-anchored viral spike protein and ACE 2 receptors, with a high affinity for SARS-CoV-2 [37]. Several mechanisms have been hypothesized to explain diarrhea in COVID-19 patients: alteration of intestinal permeability by the viral infection and subsequent malabsorption [38] and alteration of gut microbiome due to reduced uptake of dietary amino acids and increased susceptibility to intestinal inflammation associated with ACE 2 alterations [39]. Patients with gastrointestinal symptoms are more likely to be fecal virus-positive than those with respiratory symptoms, and this should have an important implication to endoscopic explorations, patient care, and infection control [35]. Patients with gastrointestinal symptoms present later than those with respiratory symptoms, have a longer period duration between symptom onset and viral load clearance, and often with severe disease $[35,40]$.

In the multicenter COVID-LIVER-CHESS study, liver injury defined as any parameter more than the upper limit of the normal value of alanine transaminase (40 IU/L), aspartate transaminase $(40 \mathrm{IU} / \mathrm{L})$, and total bilirubin (TBil $17.1 \mu \mathrm{mol} / \mathrm{L}$ ) was found in $45 \%$ of patients with COVID19. This is without any therapy including antiviral drugs, complementary and alternative medicine or non-steroidal anti-inflammatory drugs before admission. Observed abnormalities are by decreasing order elevated liver enzymes. Clinically, those patients may present without jaundice [41]. Mechanisms of liver injury in COVID-19 patients are not fully understood. SARS-CoV-2 might directly bind to ACE2positive cholangiocytes to dysregulate liver function [42]. Also, the liver might be injured by the patient immune response [43]. Liver pathological findings of COVID-19 patients showed moderate microvascular steatosis and mild lobular and portal activity [12]. Those patients with liver injury have longer mean hospital stays than patients with normal liver function [44]. Low albumin is a marker of severe infection and poor prognosis [45].
COVID-19 has implications in the course of pre-existing gastrointestinal diseases although they are not the main comorbidities found in these patients. Hepatitis B viral infection defined as a positive result on testing for hepatitis B surface antigen only was found in 2\% of COVID-19 patients without association with the severe form of the disease or poor outcome [40]. Impact on chronic liver conditions such as nonalcoholic fatty liver disease, alcohol-related liver disease, and autoimmune hepatitis needs to be further evaluated [46]. Liver transplantation might involve a risk of transmission of viral infection from donor to recipient, and therefore, donor screening and testing is crucial [47]. Whether or not patients with gastrointestinal cancers are more likely to be infected with SARS-CoV-2 than healthy individuals remains unknown [46]. Patients with inflammatory bowel disease receiving biologic or immunosuppressive agents represent a population of great concern [46]. Liver cirrhosis is one of the most common chronic liver conditions in LMIC. The impact of COVID-19 on the chronic gastrointestinal conditions has been addressed using liver cirrhosis as model. We expect a long-lasting impact on the quality of cirrhosis care with a three-wave evolution. An intense period prioritizes high-acuity care, a challenging "return to normal and a protracted period of suboptimal outcomes" [48].

Drug-induced liver injury (DILI) is a major concern during the COVID-19 pandemic. The use of lopinavir/ritonavir was found to lead to increased odds of liver injury [49]. Falcão et al. reported a 10-fold increase in serum levels of transaminases, followed by a rapid decrease after hydroxychloroquine (HCQ) withdrawal in a COVID-19 patient. The mechanism of hepatic injury related to HCQ is poorly established, and toxicity may be due to reactive metabolites or an idiosyncratic mechanism [50]. Concerning traditional medicine taken by patients as to prevent COVID-19, it can also induce DILI. Those patients often consult for upper gastrointestinal symptoms as epigastric pains or pyrosis.

Pancreatic injury occurs in $17 \%$ of patients with severe COVID-19 [51]. Their most common symptoms were fever and respiratory symptoms [52]. In this study, six out of nine patients with pancreatic injury presented abnormal blood glucose [52]. On CT scan, patients with severe COVID-19 shows changes in the pancreas, mainly focal enlargement of the pancreas or dilatation of the pancreatic duct, without acute necrosis [51]. Compared without pancreatic injury, those with pancreatic injury had severe illness on admission [52]. Three mechanisms may contribute to pancreatic injury: direct effect of the virus on pancreatic tissues since the SARS-CoV-2 receptor of ACE 2 is highly expressed in both exocrine glands and islets [51], systemic inflammatory response, and drug-related pancreatic injury considering that most of the patients received various medications [52]. 


\section{Neurological Manifestations of COVD-19}

There are literature findings associating coronavirus infections, and especially COVID-19, with neurological manifestations [53]. Mao and colleagues while studying retrospectively 214 COVID-19 hospitalized patients found that $36.4 \%$ had nervous system involvement [54]. They reported a $24.8 \%$ prevalence of central nervous system (CNS) manifestations, encompassing dizziness, headaches, impaired consciousness, and cerebrovascular lesions [54]. Likewise, Li et al. in a retrospective observational analysis of 221 admitted COVID-19 patients, reported that 11 of them developed acute ischemic stroke, and one had brain hemorrhage [55]. It could be stipulated a relationship between cerebrovascular events and increased levels of D-dimer as well as severely decreased platelet count and prolonged prothrombin time, which are frequently found among COVID-19 patients [56]. Coronavirus disease 2019 can also present as a meningitis or encephalitis (clinically with headaches, seizures, consciousness disturbances), as established by case reports confirming the presence of SARSCoV-2 in the cerebrospinal fluid of COVID-19 patients [57, 58]. Furthermore, evidences are supporting that hypoxic encephalopathy can complicate the disease [59]. Mao et al. found that $8.9 \%$ of 214 COVID-19 in-patients presented with peripheral nervous system (PNS) symptoms, the most common manifestations being taste and smell impairments [54]. Anosmia and dysgeusia have also been reported by other studies $[60,61]$. Other neurological features of COVID-19 include visual function impairment and neuralgia [54]. Interestingly, Gutiérrez-Ortiz and colleagues reported two COVID-19 patients, who respectively acutely presented with polyneuritis cranialis and Miller Fisher syndrome [62]. Miller Fisher syndrome (MFS) is a rare variant of Guillain-Barré syndrome (GBS) characterized by a classical clinical triad associating ataxia, areflexia, and ophthalmoplegia [63].

Nervous system manifestations (chiefly CNS ones) can be notably explained by neurotropic and neuroinvasive capacities of coronaviruses with subsequent inflammatory and demyelinating processes $[64,65]$. Briefly, potential mechanisms of COVID-19 neurological complications include cytokine dysregulation with upregulation of pro-inflammatory cytokine secretion (TNF-alpha, IL-1-beta, IL-6) by neuronal and glial cells $[66,67]$, peripheral immune cells (myeloid cells), transmigration [68], post-infectious autoimmunity [31, 67], and gut microbial translocation (involving the gut-brain axis) [67, 69].

\section{Mental Health Outcomes of COVID-19}

As previous outbreaks and pandemic, COVID-19 has mental health sequelae on different population groups. These groups include the general population, mental health patients, and healthcare workers, but firstly, suspected and confirmed COVID-19 patients [70, 71].
While exploring the current scientific literature, observations and studies are reporting various degrees of negative psychological and/or psychiatric issues among COVID-19 patients $[67,72,73]$. Indeed, these patients frequently experience trauma-related symptoms (i.e., stress), anxiety, and depression $[67,70,73]$. Bo and colleagues assessed posttraumatic stress (PTS) symptoms among 714 clinically stable patients with COVID-19 in China and found a prevalence rate of PTS of $96.2 \%$ [73]. Zhang et al. in a research work comparing psychological distress across populations affected by the COVID-19 pandemic obtained that $29.2 \%$ of COVID-19 had depression, with $19.3 \%$ representing severe depressive symptoms [74]. Also, they reported a $20.8 \%$ prevalence rate regarding anxiety [74]. In addition to mental health repercussions listed above, suicide cases have been reported among suspected or confirmed cases of COVID-19. This is the case of 60-year-old French medical doctor, who committed suicide and incriminated its COVID-19 diagnosis in a note left before taking his life [75]. These mental health corollaries pertained to diverse risk factors and determinants encompassing isolation, fear of death, fear of contaminating others, and social exclusion [67, 70, 73]. Nevertheless, more precise biological explanatory mechanisms are not yet elucidated. However, based on these cited deleterious mental consequences, there is a need for continuous tailored psychological supports (with adapted psychotropic treatments or not) for COVID-19 patients.

\section{Rheumatological Manifestations of COVID-19}

Rheumatological manifestations during coronavirus 2019 infection are frequent but remain benign. They include myalgias and arthralgia reported by more than two-thirds of patients $[76,77]$. They are frequently associated with other manifestations, including respiratory signs, hematological signs, and signs of myocarditis, hence sometimes mimicking the clinical presentation of systemic inflammatory disease [78]. The hypothesized mechanism is not directly related to the virus. As other respiratory viral infections, the release of cytokines observed during the infection could lead to sensitization of the sensory receptors on the muscular fibers, causing muscle weakness and pain and sometimes a slight increase in muscular enzymes as creatine phosphokinase [76, 79]. The cytokines may deposit on the joints as well, causing arthralgia which could affect several peripheral joints [80]. Till date, no direct articular effect of the virus has been found.

The clinical features of COVID-19 are a great concern in some specific and vulnerable groups. The clinical pattern observed in the context of systemic inflammatory diseases (SIDs) seems quite similar to that of patients not affected. Initially, they were believed to be at high risk of severe infection associated with immunosuppressive therapy [81]. However, the dysregulation of the immune system, the 
cytokine storm and thus a hyper-inflammatory state described in the pathophysiological mechanism of the COVID-19 infection is possibly controlled by the concomitant immunosuppressive and/or immunomodulatory treatment. Studies have therefore reported a low rate of SID flares during COVID-19 and a lower proportion of ICU admissions of patients receiving immunosuppressive and/or immunomodulatory drugs. Especially hydroxychloroquine, whose therapeutic effect vis-à-vis COVID-19 is still being studied, and interleukin 1 and 6 inhibitors, for which tocilizumab has reportedly shown an improvement [82-86]. Several studies have demonstrated safety in the use of non-steroidal anti-inflammatory drugs to control the pain. The safety of various DMARDs (diseasemodifying anti-rheumatism drugs) during the COVID-19 pandemic is commendable [87].

\section{Endocrine-Metabolic Manifestations of COVID-19}

Contrary to other systems, data on the interaction between COVID-19 and endocrine system are scarce. Some hypotheses have been postulated because many endocrine organs express ACE2 namely the pancreas, thyroid, testis, ovary, adrenal glands, and pituitary. In critically ill patients, acute pancreatitis, diabetes mellitus, hypogonadism, adrenal insufficiency, and hypothyroidism are the classical features described in the literature [88]. As for other systems, the pathophysiology of these disorders may include direct effect of SARS-CoV-2 in the cells and the effect of the cytokine storm.

\section{The Therapeutical Implication in LMICs}

In the absence of universal curative treatment, several approaches have been developed to take care of patients with COVID-19. Mild and moderate cases have often been treated symptomatically associated with general measures such as physical distancing and hygienic measures such as hand washing [2]. Severe cases are generally admitted into the ICU where they are managed with different types of experimental medications (chloroquine, hydroxychloroquine, remdesevir, lopinavir/Ritonavir, immunotherapy, traditional Chinese medicine, and/or arbitol), oxygen supplementation or mechanical ventilation, analgesics, antipyretics, enteral nutrition and glycemic control, early physical therapy, prevention of nosocomial infections, deep vein thrombosis prophylaxis, stress ulcer prophylaxis, fluid and electrolytic balance maintenance, and renal replacement therapy [89]. Despite the different treatment protocols used so far, the prognosis of critically ill patients often remains reserved, even in developed countries [90]. Recently, the use of corticosteroids was proven to improve the prognosis of patients with severe respiratory distress. Even if reserved to this specific category of patients, this constitutes good news for all, particularly because of the low cost and wide availability of dexamethasone [91-93].

The aforementioned evidence of the involvement of COVID-19 on a myriad of body systems, organs, and the psyche highly suggests that COVID-19 is a multi-systemic infectious disease and should be managed accordingly. In LMICs where the healthcare resources are limited, the therapeutic strategies apart from the public health preventive measures decreed by the WHO and national health authorities may focus more on adequate screening and close follow-ups of risk groups; organization triage by using adapted predictive scores based on clinical signs and biological markers of severity like D-dimers and lymphopenia [94]; and early multidisciplinary evaluation of the patients to reduce progression into the severe stage where capacity will be probably limited.

\section{Conclusion}

The COVID-19 pandemic is an example of a multi-systemic infectious disease that needs early collaboration with diverse clinical specialties particularly in LMICs to curb the burden of the disease.

Authors' Contributions MNT wrote the first draft in joint collaboration with FTE, JRN, GUK, and EM with respect to their field of research interest and clinical specialty. JNT critically revised the manuscript. All the authors read and approved the final manuscript.

\section{Compliance with Ethical Standards}

Conflict of Interest The authors declare that they have no competing interests.

Ethical Approval Ethical approval was not required for this manuscript due to the nature of the review.

Informed Consent NA

Abbreviations COVID-19, coronavirus 19 disease; CKD, chronic kidney disease; ALT, alanine aminotransferase; ARDS, acute respiratory distress syndrome; AST, aspartate aminotransferase; CT scan, computed tomography scan; DMARDS, disease modifying anti-rheumatism drug; ECG, electrocardiogram; ICU, intensive care unit; Ig, immunoglobulin; IL, interleukin; LMICs, low- and middle-income countries; PTS, posttraumatic stress; SID, systemic inflammatory disease; TNF, tumor necrosis factor

\section{References}

1. Guo Y-R, Cao Q-D, Hong Z-S, Tan Y-Y, Chen S-D, Jin H-J, et al. The origin, transmission and clinical therapies on coronavirus disease 2019 (COVID-19) outbreak - an update on the status. Mil Med Res. 2020;7(1):11.

2. WHO. Coronavirus disease 2019 (COVID-19) Situation Report 90. [cited 2020 Apr 19]; Available from: https://www.who.int/docs/ 
default-source/coronaviruse/situation-reports/20200419-sitrep-90covid-19.pdf?sfvrsn $=551 \mathrm{~d} 47 \mathrm{fd} 2$

3. StatPearls. Treasure Island (FL): StatPearls Publishing; 2020.

4. Guan W, Ni Z, Hu Y, Liang W, Ou C, He J, et al. Clinical characteristics of coronavirus disease 2019 in China. New England J Med. 2020 Feb 28 [cited 2020 Apr 17]; Available from: h10.1056/ NEJMoa2002032

5. Bai Y, Yao L, Wei T, Tian F, Jin D-Y, Chen L, et al. Presumed asymptomatic carrier transmission of COVID-19. JAMA. 2020;323(14):1406.

6. Wang T, Du Z, Zhu F, Cao Z, An Y, Gao Y, et al. Comorbidities and multi-organ injuries in the treatment of COVID-19. Lancet. 2020;395(10228):e52.

7. Wu Z, McGoogan JM. Characteristics of and important lessons from the coronavirus disease 2019 (COVID-19) outbreak in China. JAMA. 2020;323(13):1239.

8. Mao Y, Lin W, Wei J, Chen G. Clinical and pathological characteristics of 2019 novel coronavirus disease (COVID-19): a systematic review. Available from: https://doi.org/10.1101/2020.02.20. 20025601.

9. CDC. Hospitalization rates and characteristics of patients hospitalized with laboratory-confirmed coronavirus disease 2019 COVID-NET, 14 States, March 1-30, 2020. 2020 Apr 17;458-64.

10. Jackson DJ, Busse WW, Bacharier LB, Kattan M, O'Connor GT, Wood RA, et al. Association of respiratory allergy, asthma and expression of the SARS-CoV-2 receptor, ACE2. J Allergy Clin Immunol. 2020;146:203-206.e3.

11. Wang $\mathrm{D}, \mathrm{Hu} \mathrm{B}, \mathrm{Hu} \mathrm{C}$, Zhu F, Liu X, Zhang J, et al. Clinical characteristics of 138 hospitalized patients with 2019 novel coronavirus-infected pneumonia in Wuhan, Chima. JAMA. 2020;323(11):1061.

12. Xu Z, Shi L, Wang Y, Zhang J, Huang L, Zhang C, et al. Pathological findings of COVID-19 associated with acute respiratory distress syndrome. Lancet Respir Med. 2020;8(4):420-2.

13. Klok FA, Kruip MJHA, Van der Meer NJM, Arbous MS, Gommers DAMPJ, Kant KM, et al. Incidence of thrombotic complications in critically ill ICU patients with COVID- 19 . Thrombosis Research [Internet]. 2020 Apr [cited 2020 Apr 18]; Available from: https://linkinghub.elsevier.com/retrieve/pii/ S0049384820301201

14. Verity R, Okell LC, Dorigatti I, Winskill P, Whittaker C, Imai N, et al. Estimates of the severity of coronavirus disease 2019: a model-based analysis. The Lancet Infectious Diseases [Internet]. 2020 Mar [cited 2020 Apr 17]; Available from: https://linkinghub. elsevier.com/retrieve/pii/S1473309920302437

15. Wan Y, Shang J, Graham R, Baric RS, Li F. Receptor recognition by the novel coronavirus from Wuhan: an analysis based on decade-long structural studies of SARS coronavirus. Gallagher T, editor. Journal of Virology [Internet]. 2020 Mar 17 [cited 2020 Apr 22];94(7). Available from: https://doi.org/10.1128/JVI.0012720

16. Fang L, Karakiulakis G, Roth M. Are patients with hypertension and diabetes mellitus at increased risk for COVID-19 infection? Lancet Respir Med. 2020;8(4):e21.

17. Kassir R. Risk of COVID-19 for patients with obesity. Obesity Reviews [Internet]. 2020 Apr 13 [cited 2020 Apr 17]; Available from: https://doi.org/10.1111/obr.13034

18. Cui S, Chen S, Li X, Liu S, Wang F. Prevalence of venous thromboembolism in patients with severe novel coronavirus pneumonia. Journal of Thrombosis and Haemostasis [Internet]. 2020 Apr 9 [cited 2020 Apr 18]; Available from: https://doi.org/10.1111/jth.14830

19. Liu PP, Blet A, Smyth D, Li H. The science underlying COVID-19: implications for the cardiovascular system. Circulation [Internet]. 2020 Apr 15 [cited 2020 Apr 17]; Available from: https://doi.org/ 10.1161/CIRCULATIONAHA.120.047549
20. ACC. Ventricular arrhythmia risk due to hydroxychloroquineazithromycin treatment for COVID-19. 2020 Mar 29 [cited 2020 Apr 20]; Available from: https://www.acc.org/latest-in-cardiology/ articles/2020/03/27/14/00/ventricular-arrhythmia-risk-due-tohydroxychloroquine-azithromycin-treatment-for-covid-19

21. Diao B, Wang C, Wang R, Feng Z, Tan Y, Wang H, et al. Human kidney is a target for novel severe acute respiratory syndrome coronavirus 2 (SARS-CoV-2) Infection. medRxiv. 2020;2020.03.04.20031120.

22. Xu D, Zhang H, Gong H, Chen J, Ye J, Meng T, et al. Identification of a potential mechanism of acute kidney injury during the COVID19 outbreak: a study based on single-cell transcriptome analysis. 2020 Feb 23 [cited 2020 Apr 26]; Available from: https://www. preprints.org/manuscript/202002.0331/v1

23. Perico L, Benigni A, Remuzzi G. Should COVID-19 concern nephrologists? Why and to what extent? The emerging impasse of angiotensin blockade. Nephron. 2020;23:1-9.

24. Gabarre P, Dumas G, Dupont T, Darmon M, Azoulay E, Zafrani L. Acute kidney injury in critically ill patients with COVID-19. Intensive Care Med. 2020;46(7):1339-48.

25. Akalin E, Azzi Y, Bartash R, Seethamraju H, Parides M, Hemmige $\mathrm{V}$, et al. COVID-19 and kidney transplantation. New England J Med. 2020;0(0):null.

26. Henry BM, De Oliveira MHS, Benoit S, Plebani M, Lippi G. Hematologic, biochemical and immune biomarker abnormalities associated with severe illness and mortality in coronavirus disease 2019 (COVID-19): a meta-analysis. Clin Chem Lab Med. 2020 Apr 10;58:1021-8.

27. Shoenfeld Y. Corona (COVID-19) time musings: our involvement in COVID-19 pathogenesis, diagnosis, treatment and vaccine planning. Autoimmun Rev. 2020;5:102538.

28. Lippi G, Plebani M. The critical role of laboratory medicine during coronavirus disease 2019 (COVID-19) and other viral outbreaks. Clin Chem Lab Med. 2020;58:1063-9.

29. Lippi G, Plebani M. Laboratory abnormalities in patients with COVID-2019 infection. Clin Chem Lab Med. 2020 Mar 3;58: $1131-4$.

30. Zhang Y, Xiao M, Zhang S, Xia P, Cao W, Jiang W, et al. Coagulopathy and antiphospholipid antibodies in patients with COVID-19. N. Engl. J. Med. 2020;382(17):e38.

31. Shi Y, Wang Y, Shao C, Huang J, Gan J, Huang X, et al. COVID19 infection: the perspectives on immune responses. Cell Death Differ. 2020;23:1-4.

32. Mehta P, McAuley DF, Brown M, Sanchez E, Tattersall RS, Manson JJ, et al. COVID-19: consider cytokine storm syndromes and immunosuppression. Lancet. 2020;395(10229):1033-4.

33. Terpos E, Ntanasis-Stathopoulos I, Elalamy I, Kastritis E, Sergentanis TN, Politou M, et al. Hematological findings and complications of COVID-19. American Journal of Hematology [Internet]. n/a(n/a). Available from: https://doi.org/10.1002/ajh. 25829

34. Pan L, Mu M, Yang P, Sun Y, Wang R, Yan J, et al. Clinical characteristics of COVID-19 patients with digestive symptoms in Hubei, China: a descriptive, cross-sectional, multicenter study. Am J Gastroenterol. 2020;

35. Han C, Duan C, Zhang S, Spiegel B, Shi H, Wang W, et al. Digestive symptoms in COVID-19 patients with mild disease severity: clinical presentation, stool viral RNA testing, and outcomes. Am J Gastroenterol. 2020;115:916-23.

36. D'Amico F, Baumgart DC, Danese S, Peyrin-Biroulet L. Diarrhea during COVID-19 infection: pathogenesis, epidemiology, prevention and management. Clin Gastroenterol Hepatol. 2020;18:166372 .

37. Cui J, Li F, Shi Z-L. Origin and evolution of pathogenic coronaviruses. Nat Rev Microbiol. 2019;17(3):181-92. 
38. Gu J, Han B, Wang J. COVID-19: gastrointestinal manifestations and potential fecal-oral transmission. Gastroenterology. 2020.

39. Hashimoto T, Perlot T, Rehman A, Trichereau J, Ishiguro H, Paolino M, et al. ACE2 links amino acid malnutrition to microbial ecology and intestinal inflammation. Nature. 2012;487(7408):47781.

40. Guan W, Ni Z, Hu Y, Liang W, Ou C, He J, et al. Clinical characteristics of coronavirus disease 2019 in China. New England Journal of Medicine. 2020;0(0):null.

41. Qi X, Liu C, Jiang Z, Gu Y, Zhang G, Shao C, et al. Multicenter analysis of clinical characteristics and outcome of COVID-19 patients with liver injury. J Hepatol 2020.

42. Zhao B, Ni C, Gao R, Wang Y, Yang L, Wei J, et al. Recapitulation of SARS-CoV-2 infection and cholangiocyte damage with human liver ductal organoids. Protein Cell. 2020;17:1-5.

43. Xu L, Liu J, Lu M, Yang D, Zheng X. Liver injury during highly pathogenic human coronavirus infections. Liver Int. 2020.

44. Fan Z, Chen L, Li J, Cheng X, Jingmao Yang Null, Tian C, et al. Clinical features of COVID-19-related liver damage. Clin Gastroenterol Hepatol 2020.

45. Liu W, Tao Z-W, Lei W, Ming-Li Y, Kui L, Ling Z, et al. Analysis of factors associated with disease outcomes in hospitalized patients with 2019 novel coronavirus disease. Chin Med J 2020

46. Mao R, Liang J, Shen J, Ghosh S, Zhu L-R, Yang H, et al. Chinese society of IBD, Chinese elite IBD union, Chinese IBD quality care evaluation center committee. Implications of COVID-19 for patients with pre-existing digestive diseases. Lancet Gastroenterol Hepatol. 2020;5(5):426-8.

47. Kumar D, Tellier R, Draker R, Levy G, Humar A. Severe acute respiratory syndrome (SARS) in a liver transplant recipient and guidelines for donor SARS screening. Am J Transplant. 2003;3(8):977-81

48. Tapper EB, Asrani SK. COVID-19 pandemic will have a longlasting impact on the quality of cirrhosis care. J Hepatol 2020.

49. Cai Q, Huang D, Yu H, Zhu Z, Xia Z, Su Y, et al. Characteristics of liver tests in COVID-19 patients. J Hepatol 2020.

50. Hydroxychloroquine. LiverTox: clinical and research information on drug-induced liver injury [Internet]. Bethesda (MD): National Institute of Diabetes and Digestive and Kidney Diseases; 2012 [cited 2020 Apr 26]. Available from: http://www.ncbi.nlm.nih.gov/ books/NBK548738/

51. Liu F, Long X, Zhang B, Zhang W, Chen X, Zhang Z. ACE2 expression in pancreas may cause pancreatic damage after SARSCoV-2 infection. Clinical Gastroenterology and Hepatology [Internet]. 2020 Apr 22 [cited 2020 Apr 26];0(0). Available from: https://www.cghjournal.org/article/S1542-3565(20)30537-1/ abstract.

52. Wang F, Wang H, Fan J, Zhang Y, Wang H, Zhao Q. Pancreatic injury patterns in patients with COVID-19 pneumonia. Gastroenterology. 2020.

53. Asadi-Pooya AA, Simani L. Central nervous system manifestations of COVID-19: a systematic review. J Neurol Sci. 2020;413: 116832.

54. Mao L, Jin H, Wang M, Hu Y, Chen S, He Q, et al. Neurologic manifestations of hospitalized patients with coronavirus disease 2019 in Wuhan, China. JAMA Neurol [Internet]. 2020 Apr 10 [cited 2020 Apr 26]; Available from: https://jamanetwork.com/ journals/jamaneurology/fullarticle/2764549.

55. Li Y, Wang M, Zhou Y, Chang J, Xian Y, Mao L, et al. Acute cerebrovascular disease following COVID-19: a single center, retrospective, observational study [Internet]. Rochester, NY: Social Science Research Network; 2020 Mar. Report No.: ID 3550025. Available from: https://papers.ssrn.com/abstract $=3550025$

56. Wang Y, Wang Y, Chen Y, Qin Q. Unique epidemiological and clinical features of the emerging 2019 novel coronavirus pneumonia (COVID-19) implicate special control measures. J Med Virol 2020.

57. Moriguchi T, Harii N, Goto J, Harada D, Sugawara H, Takamino J, et al. A first case of meningitis/encephalitis associated with SARSCoronavirus-2. Int J Infect Dis. 2020;94:55-8.

58. Wu Y, Xu X, Chen Z, Duan J, Hashimoto K, Yang L, et al. Nervous system involvement after infection with COVID-19 and other coronaviruses. Brain Behav Immun 2020;

59. Chen T, Wu D, Chen H, Yan W, Yang D, Chen G, et al. Clinical characteristics of 113 deceased patients with coronavirus disease 2019: retrospective study. BMJ [Internet]. 2020 Mar 26 [cited 2020 Apr 26];368. Available from: https://www.bmj.com/content/ 368/bmj.m1091.

60. Russell B, Moss C, Rigg A, Hopkins C, Papa S, Van Hemelrijck M. Anosmia and ageusia are emerging as symptoms in patients with COVID-19: what does the current evidence say? Ecancermedicalscience [Internet]. 2020 Apr 3 [cited 2020 Apr 26];14. Available from: https://www.ncbi.nlm.nih.gov/pmc/ articles/PMC7134577/.

61. Giacomelli A, Pezzati L, Conti F, Bernacchia D, Siano M, Oreni L, Rusconi S., Gervasoni C., Ridolfo A.L., Rizzardini G., Antinori S., Galli M. Self-reported olfactory and taste disorders in SARS-CoV2 patients: a cross-sectional study. Clin Infect Dis 2020;

62. Gutiérrez-Ortiz C, Méndez A, Rodrigo-Rey S, San Pedro-Murillo E, Bermejo-Guerrero L, Gordo-Mañas R, et al. Miller Fisher syndrome and polyneuritis cranialis in COVID-19. Neurology. 2020.

63. Fisher M. An unusual variant of acute idiopathic polyneuritis (syndrome of ophthalmoplegia, ataxia and areflexia). N Engl J Med. 1956;255(2):57-65.

64. Baig AM, Khaleeq A, Ali U, Syeda H. Evidence of the COVID-19 virus targeting the CNS: tissue distribution, host-virus interaction, and proposed neurotropic mechanisms. ACS Chem Neurosci. 2020;11(7):995-8.

65. Li Y-C, Bai W-Z, Hashikawa T. The neuroinvasive potential of SARS-CoV2 may play a role in the respiratory failure of COVID19 patients. J Med Virol. 2020;92(6):552-5.

66. Lipworth B, Chan R, Lipworth S, Rui Wen, Kuo C. Weathering the cytokine storm in susceptible patients with severe SARS-CoV-2 infection. J Allergy Clin Immunol Pract [Internet]. 2020 Apr 18 [cited 2020 Apr 26]; Available from: https://www.ncbi.nlm.nih. gov/pmc/articles/PMC7165083/.

67. Troyer EA, Kohn JN, Hong S. Are we facing a crashing wave of neuropsychiatric sequelae of COVID-19? Neuropsychiatric symptoms and potential immunologic mechanisms. Brain Behav Immun. 2020.

68. Desforges M, Miletti TC, Gagnon M, Talbot PJ. Activation of human monocytes after infection by human coronavirus 229E. Virus Res. 2007;130(1):228-40.

69. Gao QY, Chen YX, Fang JY. 2019 novel coronavirus infection and gastrointestinal tract. J Dig Dis. 2020 Mar;21(3):125-6.

70. Rajkumar RP. COVID-19 and mental health: a review of the existing literature. Asian J Psychiatr. 2020;52:102066.

71. Torales J, O'Higgins M, Castaldelli-Maia JM, Ventriglio A. The outbreak of COVID-19 coronavirus and its impact on global mental health. Int J Soc Psychiatry. 2020;31:20764020915212.

72. Yao H, Chen J-H, Xu Y-F. Patients with mental health disorders in the COVID-19 epidemic. Lancet Psychiatry. 2020;7(4):e21.

73. Bo H-X, Li W, Yang Y, Wang Y, Zhang Q, Cheung T, et al. Posttraumatic stress symptoms and attitude toward crisis mental health services among clinically stable patients with COVID-19 in China. Psychological Medicine. undefined/ed;1-7.

74. Zhang J, Lu H, Zeng H, Zhang S, Du Q, Jiang T, et al. The differential psychological distress of populations affected by the COVID19 pandemic. Brain Behav Immun. 2020;87:49-50.

75. French doctor commits suicide after Covid-19 diagnosis [Internet]. NST Online. [cited 2020 Apr 25]. Available from: https://www.nst. 
com.my/world/world/2020/04/581620/french-doctor-commitssuicide-after-covid-19-diagnosis.

76. Richardson S, Hirsch JS, Narasimhan M, Crawford JM, McGinn T, Davidson KW, et al. Presenting Characteristics, Comorbidities, and outcomes among 5700 patients hospitalized with COVID-19 in the New York city area. JAMA [Internet]. 2020 Apr 22 [cited 2020 Apr 25]; Available from: https://jamanetwork.com/journals/jama/ fullarticle/2765184.

77. Licciardi F, Giani T, Baldini L, Favalli EG, Caporali R, Cimaz R. COVID-19 and what pediatric rheumatologists should know: a review from a highly affected country. Pediatr Rheumatol. 2020;18(1):35.

78. Misra DP, Agarwal V, Gasparyan AY, Zimba O. Rheumatologists' perspective on coronavirus disease 19 (COVID-19) and potential therapeutic targets. Clin Rheumatol. 2020 Apr;10:1-8.

79. Light AR, Vierck CJ, Light KC. Myalgia and fatigue: translation from mouse sensory neurons to fibromyalgia and chronic fatigue syndromes. In: Kruger L, Light AR, editors. Translational pain research: from mouse to man [internet]. Boca Raton: CRC Press/ Taylor \& Francis; 2010. Available from: http://www.ncbi.nlm.nih. gov/books/NBK57253/.

80. Tiwari V, Bergman MJ. Viral arthritis. StatPearls [Internet]. Treasure Island (FL): StatPearls Publishing; 2020. Available from: http://www.ncbi.nlm.nih.gov/books/NBK531507/.

81. Favalli EG, Ingegnoli F, De Lucia O, Cincinelli G, Cimaz R, Caporali R. COVID-19 infection and rheumatoid arthritis: faraway, so close! Autoimmun Rev [Internet]. 2020 Mar 20; Available from: https://www.ncbi.nlm.nih.gov/pmc/articles/PMC7102591/

82. Giamarellos-Bourboulis EJ, Netea MG, Rovina N, Akinosoglou K, Antoniadou A, Antonakos N, et al. Complex immune dysregulation in COVID-19 patients with severe respiratory failure. Cell Host Microbe [Internet]. 2020 Apr 21; Available from: https://www. ncbi.nlm.nih.gov/pmc/articles/PMC7172841/.

83. Ceribelli A, Motta F, De Santis M, Ansari AA, Ridgway WM, Gershwin ME, et al. Recommendations for coronavirus infection in rheumatic diseases treated with biologic therapy. J Autoimmun. 2020;109:102442.

84. Zhao M. Cytokine storm and immunomodulatory therapy in COVID-19: role of chloroquine and anti-IL-6 monoclonal antibodies. Int J Antimicrob Agents [Internet]. 2020 Apr 16; Available from: https://www.ncbi.nlm.nih.gov/pmc/articles/PMC7161506/.

85. Yazdany J, Kim AHJ. Use of hydroxychloroquine and chloroquine during the COVID-19 pandemic: what every clinician should know. Annals of Internal Medicine [Internet]. [cited 2020 Apr 25]; Available from: https://www.ncbi.nlm.nih.gov/pmc/ articles/PMC7138336/.

86. Monti S, Balduzzi S, Delvino P, Bellis E, Quadrelli VS, Montecucco C. Clinical course of COVID-19 in a series of patients with chronic arthritis treated with immunosuppressive targeted therapies. Ann Rheum Dis. 2020 May 1;79(5):667-8.

87. Tufan A, Avanoğlu Güler A, Matucci-Cerinic M. COVID-19, immune system response, hyperinflammation and repurposing antirheumatic drugs. Turk J Med Sci. 2020;50(SI-1):620-32.

88. Pal R, Banerjee M. COVID-19 and the endocrine system: exploring the unexplored. J Endocrinol Investig. 2020;43(7):1027-31.

89. Tobaiqy M, Qashqary M, Al-Dahery S, Mujallad A, Hershan AA, Kamal MA, et al. Therapeutic management of COVID-19 patients: a systematic review. Infect Prevent Pract 2020;100061.

90. Vincent J-L, Taccone FS. Understanding pathways to death in patients with COVID-19. The Lancet Respiratory Medicine [Internet]. 2020 Apr [cited 2020 Apr 28]; Available from: https://linkinghub. elsevier.com/retrieve/pii/S221326002030165X.

91. Pennica A, Conforti G, Falangone F, Martocchia A, Tafaro L, Sentimentale A, et al. Clinical management of adult coronavirus infection disease 2019 (COVID-19) positive in the setting of low and medium intensity of care: a short practical review. SN Comprehensive Clinical Medicine. 2020;2(6):694-9.

92. Ye Z, Wang Y, Colunga-Lozano LE, Prasad M, Tangamornsuksan W, Rochwerg B, et al. Efficacy and safety of corticosteroids in COVID-19 based on evidence for COVID-19, other coronavirus infections, influenza, community-acquired pneumonia and acute respiratory distress syndrome: a systematic review and meta-analysis. Can Med Assoc J. 2020;192(27):E756-67.

93. Ledford H. Coronavirus breakthrough: dexamethasone is first drug shown to save lives. Nature. 2020;582(7813):469-9.

94. Phua J, Weng L, Ling L, Egi M, Lim C-M, Divatia JV, et al. Intensive care management of coronavirus disease 2019 (COVID19): challenges and recommendations. The Lancet Respiratory Medicine [Internet]. 2020 Apr [cited 2020 Apr 28]; Available from: https://linkinghub.elsevier.com/retrieve/pii/S2213260020301612.

What is already known on this topic? SARS-CoV-2 affects mainly the respiratory and cardiovascular systems

\section{What this study adds?}

1. Apart from the respiratory and cardiovascular systems, SARS-CoV-2 affects a broad range of body organs and should be considered as a multisystemic infectious disease.

2. Therapeutic implications in LMICs include early multidisciplinary collaboration to prevent death in severe cases.

Publisher's Note Springer Nature remains neutral with regard to jurisdictional claims in published maps and institutional affiliations. 